\title{
DISCIPLINAR E CONSTRANGER: O CORPO-CRIANÇA E SEU (NÃO)LUGAR NAS INSTITUIÇÕES EDUCATIVAS ${ }^{1}$
}

\author{
Aline Cristiane Ribeiro Ferreira dos Santos \\ AliandRA CRISTINA MESOMO LIRA \\ Universidade Estadual do Centro-Oeste (UNICENTRO), Guarapuava, Paraná, Brasil
}

\begin{abstract}
Resumo: $\mathrm{O}$ artigo objetiva refletir sobre o corpo e a corporeidade infantil e como são vividos e constituídos nas instituições educativas. O texto é de natureza bibliográfica e as reflexões críticas empreendidas nos auxiliam a reconhecer que as práticas, espaços e relações estabelecidas atuam para disciplinar e constranger os corpos infantis com vistas a produzir o corpo-aluno. A partir da base teórica, foi possível reconhecer como, historicamente, a educação dirigida aos sujeitos infantis transforma o corpo-criança em corpo-aluno, processo instaurado desde a Educação Infantil a partir das práticas e rituais instituídos e ancorados em um conjunto de estratégias de vigilância, sanções e punições. As ponderações acerca dos modos de ser dos sujeitos infantis nas instituições educativas evidenciam que o corpo e a corporeidade passam, desde cedo, a ser objeto de investidas que acabam por anular as características infantis e atuar na constituição de alunos ajustados ao sistema escolar.
\end{abstract}

Palavras-chave: Corpo. Educação infantil. Relações de poder.

INTRODUÇÃO

O ponto de partida para essa reflexão considera a realidade das instituições de Educação Infantil, marcada por rotinas cujas práticas atravessam os corpos infantis e atuam sobre a constituição de suas subjetividades. Barbosa (2006) e Lira (2008), dentre outros autores, refletem sobre os processos de escolarização pautados em práticas pedagógicas controladoras, geralmente organizadas em cotidianos rígidos no controle dos tempos e atividades, e como tais encaminhamentos acabam por limitar as participações infantis e constranger a potência de vida dos corpos das crianças. $O$ brincar, como atividade essencial e formadora, acaba anulado ou limitado a poucos momentos, sendo privilegiadas atividades no papel, dentro de sala, sob o olhar vigilante do professor.

No processo de escolarização, temos observado, a partir de nossas experiências, um atropelo da infância que passa pelo controle dos corpos e, de maneira geral, tudo aquilo que a constitui, contextos em que o corpo-criança é transformado no corpo aluno. Esses binômios são propostos para nossa reflexão, pois buscamos um termo que problematizasse o corpo enquanto criança diferenciado do corpo do aluno, ou seja,

\footnotetext{
${ }^{1} \mathrm{O}$ artigo apresenta reflexões oriundas de dissertação de mestrado de Santos (2020).
} 
como forma de demarcar o papel da disciplina, do controle e das imposições institucionalizadas na (con)formação dos corpos infantis. A escola, historicamente, foi descrita como uma instituição disciplinar, assentada no controle e na vigilância de comportamentos e pensamentos como formas eficazes de exercício do poder, buscando a (con)formação de corpos dóceis desde a mais tenra idade. É fato que o domínio do corpo-criança não se faz apenas pela via escolar, uma vez que, socialmente, temos instaurado um conjunto de aparatos, especialmente com a tecnologia, que fazem esse controle e impõem formas de vigilância e penalidades tendo o corpo como alvo. Quando pensamos num corpo docilizado, não estamos nos remetendo somente a um corpo imóvel, mas sim ao corpo produtivo, formatado na instituição disciplinar em sua máxima potência, aquele que responde aos estímulos prontamente, que não subverte, embora a resistência seja sempre possível, como nos ensinou Foucault (1999).

Desse modo, a transição de um corpo-criança para um corpo-aluno, nas instituições educativas, é um processo acelerado a partir das práticas e rituais instituídos, uma vez que, em pouco tempo, a cultura escolar impõe um conjunto de recomendações, vigilâncias e investimentos aos corpos e mentes infantis, que se intensificam cotidianamente. Considerando essas questões, a reflexão aqui apresentada, de cunho teórico, problematiza o corpo e a corporeidade, suas potencialidades, limites e impactos ao ser criança no âmbito escolar.

\section{CORPO E CORPOREIDADE: CONCEPÇÕES E O PAPEL DA CULTURA}

A perspectiva foucaultiana nos apresenta o conceito de governo, entendido como o agir sobre a conduta dos outros, não somente num sentido constritivo, controlador, mas essencialmente produtivo dos comportamentos, ações e pensamentos desejáveis. Esse processo disciplinar se ancora em relações de poder que emanam de diferentes sujeitos e instituições, ou seja, está capilarizado na sociedade e atua sobre os indivíduos e as populações (FOUCAULT, 1999), tendo impacto direto sobre seus corpos.

Do ponto de vista biológico, o corpo passou a ser objeto de estudo com os primeiros anatomistas e médicos egípcios os quais, segundo Melo (1989), tinham finalidade religiosa. Os mesopotâmios o consideravam tão importante que lhes concederam destaque no Código de $\mathrm{Hamurabi}^{2}$, mas foi com os gregos que houve um avanço no estudo da anatomia, uma vez que todo o guerreiro precisava saber extrair a ponta de uma flecha cravada no corpo.

Os homens que guerreavam eram conhecedores de ossos, juntas, músculos e tendões do corpo e não se aprofundaram mais nesse conhecimento por questões religiosas que pregavam que os corpos não deveriam ser violados (CHAGAS, 2001). Com Hipócrates $^{3}$, foi possível conceber o corpo como separado da religiosidade, para que este pudesse ser estudado e, possivelmente, curado.

Os estudos do corpo impulsionaram, mais tardiamente, o interesse pelo funcionamento da mente, primeiramente entendida de modo separado, pela concepção

${ }^{2}$ O Código de Hamurabi é um conjunto de leis que foram criadas por volta de 1780 a.C., na Mesopotâmia.

${ }^{3}$ Médico e filósofo grego, considerado o pai da medicina ocidental. 
dualista do cartesianismo, e, depois, corpo e mente como interligados. O cartesianismo refere-se ao filósofo francês René Descartes (1596-1650), cujo pensamento expresso em suas obras ${ }^{4}$ volta-se para o problema do conhecimento. Descartes defendia a divisão entre matéria (corpo) e pensamento (substância pensante), acreditando que eram independentes e separados um do outro, filosofia a qual estruturou a cisão entre corpo e mente. Tais ideias acabaram por orientar práticas pedagógicas nas quais o pensamento tem prevalência sobre o corpo, sendo este negado ou subjugado, concepção que ainda prevalece no campo educativo.

Séculos depois, na contramão do pensamento cartesiano, Marcel Mauss (18721950), antropólogo e sociólogo francês, foi pioneiro na tentativa de superar o entendimento dualista a respeito do corpo, justificando que toda a técnica corporal é tradicional: "Entendo por essa expressão as maneiras pelas quais os homens, de sociedade a sociedade, de uma forma tradicional, sabem servir-se de seu corpo. Em todo caso, convém proceder do concreto ao abstrato, não inversamente" (MAUSS, 1974, p. 401). Ainda nas palavras do pensador: "Chamo técnica um ato tradicional eficaz (e vejam que nisso não difere do ato mágico, religioso, simbólico). [...] Não há técnica e não há transmissão se não houver tradição. Eis em que o homem se distingue antes de tudo dos animais: pela transmissão de suas técnicas" (p. 407).

Mauss (1974) procurou relacionar a esfera biológica, psicológica e social para poder pensar no humano como um ser integrado, total e não dividido, uma vez que, em seu entender, em qualquer realização humana, podem ser encontradas as três dimensões. Esse entendimento é conceituado como fato social total (DAOLIO; RIGONEI; ROBLE, 2012), buscando superar o dualismo imposto pela filosofia cartesiana.

Ampliando as discussões de Mauss (1974), Maurice Merleau-Ponty ${ }^{5}$ (1908-1961) apresenta uma filosofia fenomenológica que descortina as relações entre o corpo e o mundo, sugerindo que é o corpo que conduz essas percepções. Para Merleau-Ponty (2018, p. 279), "O pensamento objetivo ignora o sujeito da percepção. Isso ocorre porque ele se dá no mundo inteiramente pronto [...]", desse modo, reconhecemos que, para o filósofo, é o corpo que vai em direção a uma adesão social. Daolio, Rigonei e Roble (2012, p. 190), ao analisarem os postulados do pensador, esclarecem que, para ele, a relação entre o indivíduo e a coletividade não é negada, pois "[...] considera o movimento de significação como algo construído pela coletividade, possibilitado pela vida social".

Nas próprias palavras do filósofo, "[...] não há vida em grupo que nos livre do peso de nós mesmos, que nos dispense de ter uma opinião; e não existe vida 'interior' que não seja como uma primeira experiência de nossas relações com o outro" (MERLEAU-PONTY, 2004, p. 50), ou seja, nosso modo de ser e pensar relaciona-se com o que somos, o contexto e com quem convivemos.

As compreensões do corpo como não separado da mente, mas sim integrado e partícipe da sociedade, acabaram por modificar entendimentos ganhando força a perspectiva da indivisibilidade entre corpo e mente. Esses estudos revelam que o corpo não é apenas instrumento, mas uma condição permanente da experiência, e esta "[...] não se apresenta como um acontecimento no mundo ao qual se possa aplicar, por exemplo, a categoria da causalidade, mas a cada momento como uma recriação ou uma reconstituição do mundo" (MERLEAU-PONTY, 2018, p. 279).

\footnotetext{
${ }^{4}$ Discurso do Método (1637) e Meditações Metafísicas (1641).

5 Filósofo Francês.

Inter-Ação, Goiânia, v.45, n.3, p. 906-922, set./dez. 2020. Disponível em: <http://dx.doi.org/10.5216/ia.v45i3.64193>.
} 
A mudança de perspectiva passa então a considerar a indivisibilidade entre corpo e mente, além de intensificar o debate a respeito da corporeidade empreendido por vários autores, incluindo Rudolf Laban ${ }^{6}$, o qual entendia que "O corpo é nosso instrumento de expressão por via do movimento [...]. Cada ação de uma parte particular do corpo deve ser entendida em relação ao todo que sempre será afetado" (LABAN, 1978, p. 67). As ideias de Laban reforçam a compreensão do corpo como passível de atravessamentos sociais, destacando que os movimentos expressivos, a dança e o espaço são aspectos que precisam ser considerados e inseridos na educação formal.

A partir dos autores mencionados, compartilhamos o entendimento de que $o$ corpo tem grande relação com a cultura, em razão de que esse, diariamente, é permeado por inúmeras informações e ações, que não só passam pelos corpos dos sujeitos, mas também por seus sentidos, transformando-os e não necessariamente movimentando-os. Isso agrega um potencial enorme ao corpo e o reconhece como elemento importante na constituição das subjetividades, nas formas de ser, pensar e agir dos indivíduos.

Le Breton (2007) sugere que as ações do corpo envolvem a mediação de toda a corporeidade, mesmo que essas atuações sejam mínimas, fúteis e cotidianas, pois permitem que o humano coloque significações precisas no mundo que o cerca. Entende-se que o autor fala sobre o corpo como ponto onde se recebe as informações do mundo, as quais são reestruturadas e devolvidas nas relações estabelecidas dos sujeitos entre si e com o meio, num ciclo ininterrupto.

Do corpo nascem e se propagam as significações que fundamentam a existência individual e coletiva; ele é o eixo da relação com o mundo, o lugar e o tempo nos quais a existência torna forma através da fisionomia singular de um ator. Através do corpo, o homem apropria-se da substância de sua vida traduzindo-a para os outros, servindo-se dos sistemas simbólicos que compartilha com os membros da comunidade (LE BRETON, 2007, p. 7).

Fernandes (2009) argumenta que não é possível entender o corpo humano apenas como matéria, pois nele habitam o biológico e o social que funcionam em profunda interação, ou seja, a parte física e funcional existe também em função dos aspectos culturais que envolvem os sujeitos cotidianamente. A autora, apoiada em Novaes (2006, apud FERNANDES, 2009, p. 1052), aponta que "[...] os corpos não operam no mundo social como coisas 'em si mesmas', ao contrário, a sua capacidade de operar é mediada pela cultura, ou seja, apesar de todos os seres humanos terem corpos, estes são representados, usados, controlados e concebidos de acordo com a cultura". Destarte, compreende-se que não é o corpo biológico que orienta os comportamentos, mas a cultura que modifica o corpo biológico.

Gomes (2011, p. 2277) revela seu olhar sobre as ideias de Le Breton no que diz respeito à bipolaridade do corpo:

\footnotetext{
${ }^{6}$ Dançarino, coreógrafo, teatrólogo, musicólogo, intérprete, considerado como o maior teórico da dança do século XX e como o'pai da dança-teatro'. 
SANTOS, A. C. N. DE $;$ LIRA, A. C. M

[...] ao longo do tempo, veio sendo construída uma paradoxal concepção acerca do corpo. De um lado, ele é visto como o demarcador das fronteiras entre o indivíduo e o mundo; de outro, é concebido como dissociado do homem. Em outras palavras, instalase uma bipolaridade: uma visão do corpo mais como um ter do que um ser, em que o homem não só se distancia do corpo, mas também o deprecia, e outra que faz do corpo a identidade do homem, produzindo no indivíduo um sentimento novo de ser ele mesmo, antes de ser membro de uma comunidade.

Nesse sentido, os estudos sobre o corpo, que o analisam em sua dimensão social, consideram um contexto para além da matéria física, o que afeta e orienta as inúmeras relações e experiências dos sujeitos consigo mesmo, com os outros e com o mundo. Corpo e meio social são interdependentes e, em cada ambiente, o corpo reage e se move de uma forma, seja por conveniência ou obrigação da relação que se estabelece com o meio inserido.

Como pontua Laban (1978, p. 19), "O homem se movimenta a fim de satisfazer uma necessidade [...]", a qual pode ser dirigida tanto a um objeto tangível quanto intangível. Assim, os movimentos seriam evidências tanto de um estado de espírito quanto da personalidade, influenciados pelo meio no qual está inserido o ser que se move.

Salvador (2012, p. 13), ao descrever o princípio da humanidade, revela que a única posse do homem primitivo era o seu corpo: "Era com seu corpo que o homem primitivo traçava suas relações com todo universo ao qual pertencia. Essa relação era completamente instintiva e ele precisava de seu corpo para tudo, sendo assim, extremamente dependente dele, ainda de que maneira irracional". Embora os tempos sejam outros, ainda são as necessidades básicas e motivações sociais que regem os movimentos, entretanto, compreende-se pelos estudos sociais que não há um elemento no corpo que seja somente biológico, pois a necessidade cultural participa dessa construção.

Do ponto de vista físico, anatômico, cabeça, tronco, membros e órgãos funcionam em harmonia quando saudáveis. Contudo, essa estrutura corporal e funcional é atravessada pelos elementos da cultura, que inclui costumes, hábitos, que variam entre os grupos e lugares. No campo da medicina, o estudo do corpo se volta para a prevenção, manutenção e a restauração da saúde e, mesmo assim, defronta-se com questões ligadas originalmente à vida social (como restrições de ordem religiosa para transfusões de sangue, por exemplo), ou seja, o corpo é biológico, mas socialmente informado. Considerando as questões sociais e culturais da modernidade, o corpo se torna alvo de uma série de agenciamentos, restrições e castigos, de exercício do poder. A história do corpo está atrelada à história da humanidade, a qual revela que a política, a economia e a religião interferem sobre a construção da moral e dos comportamentos. Assim, o corpo é a materialidade da existência e campo do exercício do poder, que é produtivo e não apenas restritivo. Para Foucault (1999, p. 178),

[...] o controle disciplinar não consiste simplesmente em ensinar ou impor uma série de gestos definidos; impõe a melhor relação entre um gesto e a atitude global do corpo, que é sua condição de 
eficácia e de rapidez. No bom emprego do corpo, que permite um bom emprego do tempo, nada deve ficar ocioso ou inútil: tudo deve ser chamado a formar o suporte do ato requerido. Um corpo bem disciplinado forma o contexto de realização do mínimo gesto.

Foucault se dedicou a estudar as relações entre os sujeitos e o poder, reconhecendo o corpo como passível de dominação, pois, para o filósofo, é ele que sustenta e expressa as forças de poder e de saber, as quais são articuladas estrategicamente na sociedade disciplinar, em especial, nas práticas implementadas institucionalmente. Essa sociedade disciplinar a que Foucault $(2015$, p. 243) se refere é "[...] dotada de aparatos cuja forma é a sequestração, cuja finalidade é a constituição de uma força de trabalho e cujo instrumento é a aquisição de disciplina ou hábitos". Igrejas, escolas, prisões, fábricas, juntamente com a família e, mais recentemente, a mídia se constituem nos principais esteios formativos cujo alvo são os corpos em todas as dimensões. As práticas culturais organizadas e vivenciadas, nesses contextos, sustentamse em relações de poder que são em sua essência produtivas.

[...] é possível entender o corpo como resultado provisório de diversas pedagogias que o conformam em determinadas épocas e lugares, que adquire diferentes sentidos no momento em que é investido por um poder regulador que o ajusta em seus detalhes, impondo limitações, autorizações e obrigações, para além de sua condição fisiológica. Considerando essa perspectiva, o corpo encarna as concepções que orientam determinada sociedade, modificando-se conforme as transformações que ocorrem nesse contexto. Essas concepções são produzidas através dos diferentes saberes e práticas sociais, as quais produzem efeitos e instituem verdades, excluindo e incluindo corpos sujeitos e grupos (FERNANDES, 2009, p. 1052).

Esses postulados se mostram extremamente relevantes, pois o olhar deve se voltar aos corpos infantis atravessados pelos aspectos sociais, em especial os escolares, cujas práticas potencializam comportamentos desejados, punem os indesejados, promovem adaptações, restrições, num universo em que as relações de poder mostram seu viés proibitivo e produtivo. O conceito de corporeidade, ancorado nos estudos de Merleau-Ponty, bem como os postulados de Foucault $(2015 ; 1999)$, nos ajuda a compreender como esse corpo (sobre)vive e é constituído nos contextos educacionais. A escola, historicamente, tem associado a ideia de aprendizagem à imobilidade ou ao controle dos movimentos, como nos revelam Probst e Kraemer (2012, p. 508):

[...] a escola é uma instituição social e, portanto, intimamente ligada ao todo da sociedade, pode-se dizer que as práticas escolares trazem consigo as marcas da cultura e das relações sociais que se estabelecem no contexto em que está inserida. Muitas vezes não se atenta, porém, ao fato de que a sociedade, bem como os modos de se representar o corpo e de utilizá-lo, ajustá-lo, modificá-lo na escola são historicamente construídos, trazendo consigo heranças de 
SANTOS, A. C. N. DE $;$ LIRA, A. C. M

outras épocas, quando ainda a fábrica era o modelo de produtividade para a escola.

Tanto na sociedade como nas instituições educativas, ainda estão perceptíveis e atuantes concepções baseadas na dualidade enaltecida pelo cartesianismo, com a separação entre corpo e mente, pois: "Ser criança', nesse contexto, é, então, ajustar o corpo a um padrão considerado adequado pela burocracia escolar" (PROBST; KRAEMER, 2012, p. 508). A dicotomia se expressa nas práticas e na atuação dos sujeitos: "Na escola ainda há, no entanto, um preconceito contra o movimento. Os adultos, em sua maioria, não se movimentam e reprimem a soltura das crianças. Isso começa em casa e se prolonga na escola" (PROBST; KRAEMER, 2012, p. 518).

Assim, a considerar as práticas instituídas nas instituições educativas, o corpocriança é transformado em corpo-aluno. Com o propósito de imobilidade, de um corpo mecanizado, os contextos escolares valorizam a repetição ao invés da criação, o individualismo em oposição às práticas colaborativas, atuando, de modo controlado, sobre os movimentos, mas também nas percepções e modos de aprender da criança.

Contudo, a imobilidade compromete e bloqueia as experiências dos sujeitos no mundo, pois, como pontua Nobrega (2008), é no movimento que o corpo vive, se comunica, percebe, cria, aprende, interage. A troca constante sujeito-corpo-mundo se dá, também, no descanso, que permite reflexão, pensamentos diversos, internalização de percepções.

Nesse panorama, reconhecemos que pontuar como historicamente as ideias e compreensões acerca do corpo foram se constituindo é falar sobre as transformações da humanidade (SALVADOR, 2012), sendo importante considerar que o conceito de corporeidade não se refere apenas ao corpo e ao movimento, mas engloba as relações vividas no meio sociocultural em que os corpos estão inseridos e são construídos.

Santin (1993) lembra que a corporeidade não é um conceito concreto e sim abstrato, pois transcende os aspectos físicos. Como nos lembra o autor, mesmo quando há uma indicação de cultivo do corpo, este ainda é visto como ferramenta, objetificado, já que espelha a cultura do corpo separado da mente, não contemplando a noção de corporeidade. Para Martins (2015, p. 163), "A corporeidade é o elemento de visibilidade dos embates do 'corpo' com o mundo [...]", sendo esses confrontos consequências histórico-culturais que reconstroem continuamente os corpos. Destarte, os espaços, tempos, sujeitos e práticas atuam sobre a constituição dos corpos e a vivência da corporeidade.

Segundo Gonçalves (2001), o ser humano realiza inúmeras variações no que diz respeito a suas concepções, trato do corpo e comportamento, e isso revela não somente uma apresentação ao mundo, mas também a relação desse corpo com o contexto social que o cerca, variando desde os pequenos gestos locomotores até as ações. Movimentos cotidianos, incluindo formas simbólicas de expressão, ideias sobre seu corpo e os impulsos e necessidades fazem parte de nosso dia a dia e incluem diferentes aspectos que revelam as variações das técnicas corporais entre si descritas por Mauss (1974).

Em função do lugar, da classe social, do gênero e da idade, nossos corpos assumem diferentes posições e ações, sendo possível reconhecer que a corporeidade inclui os reflexos da sociedade no corpo. O corpo-criança, nesse universo multifacetado, desde cedo, torna-se alvo do exercício do poder, que subjuga, controla e produz 
comportamentos desejáveis. Como registra Le Breton (2007), as condições do lugar e a época do nascimento impõem a interiorização de modos de vida e vivência corporal nas sociedades humanas.

Entretanto, a preocupação em sobrepujar o dualismo entre corpo e mente não ficou apenas restrita à Sociologia e à Filosofia. Cabe registrar que, nos estudos do corpo e suas relações com o mundo, destacaram-se alguns pioneiros da dança moderna, como Isadora Duncan ${ }^{7}$ (1877-1927), bailarina norte-americana. Duncan fundou escolas as quais por meio da educação do movimento e da informação cultural poderiam levar ao desenvolvimento social, uma vez que a bailarina acreditava que uma criança bem formada corporalmente e em contato com a natureza dos gestos e da vida seria fundamental para tal feito.

A corporeidade inclui reconhecer a dimensão biológica e, mais especialmente, o pertencimento social de nossos corpos, a forma de estar no mundo. Nos contextos educativos, os corpos docentes são vigorosos enquanto veículo de comunicação e os corpos das crianças encerram muitas possibilidades que precisam vir à tona, superando os planejamentos engessados e considerando o corpo como um território potente de criatividade e invenções (LÓPEZ-LÓPEZ; GALDINO, 2020).

São diferentes possibilidades para concretizar essa potencialidade e enfrentar a rigidez das regras que atravessam os corpos. Infante $(2011$, p. 9$)$ considera a pesquisa da movimentação na dança e concebe que o pensar antes da movimentação aparece como elemento necessário para compreender esse corpo novo que surge a cada dia: "Um corpo autêntico, cheio de vida e energia, capaz de assimilar conceitos e conhecimentos diversos para desenvolver as próprias habilidades [...] sem, necessariamente executá-los em exercícios". As compreensões de corpo e corporeidade nos encaminham para pensar em como se dá a (con)formação dos corpos infantis, aspecto sobre o qual refletimos a seguir.

CRIANÇA, CORPO E CORPOREIDADE: A CONSTITUIÇÃO DOS MODOS DE SER DOS SUJEITOS INFANTIS

Ao proferir a palavra criança, imaginamos um corpo cheio de vida, energia e disposição, que se mostra idealizado frente às muitas restrições e exigências da contemporaneidade, nas mais variadas instâncias sociais. De fato, as crianças, embora paulatinamente internalizem um controle de seus corpos, ainda conseguem manter uma vivência corporal que, em alguns momentos, afronta e subverte os limites da disciplina. Pensemos, por exemplo, no ato de aprender a andar de bicicleta, situação em que o corpo tenta buscar o equilíbrio aliado à destreza psicomotora, à aventura, à sensação de liberdade, à frustração ao cair e ao ímpeto de tentar novamente. Ou ainda, as brincadeiras escondidas, à revelia dos pais, dos adultos, dos professores, com um corpo vivo, mas vigilante.

O corpo traz uma história, uma espécie de memória, nos tendões, nos órgãos, no padrão da respiração. Memória afetiva dos tempos

\footnotetext{
${ }^{7}$ Angela Isadora Dunkun foi bailarina e coreografa. É tida como a precursora da dança moderna.
} 
SANTOS, A. C. N. DE $;$ LIRA, A. C. M

de infância, memória muscular do desenvolvimento motor nos primeiros anos de vida, e também memória de cada tombo, cada salto, cada cambalhota, cada dança (VIANNA; CASTILHO, 2002, p. 25).

A referência ao corpo-criança diz respeito à maneira como a criança vive sua infância de corpo inteiro, cujas experiências estimulam suas percepções sobre o mundo e proporcionam novas ressignificações a todo o momento, dentro da escola ou mesmo fora dela. Como lembra Colello (1993, p. 59), "[...] o corpo, tal como as palavras, transmite formas de ser e de pensar, modos de se fazer presente no mundo e de interagir com os demais".

A concepção de criança assumida neste texto é a de um sujeito capaz, que cria, inventa, participa, interage com as situações que vivencia e com o mundo que a cerca (BRASIL, 2009). Um sujeito infantil que, na relação com a cultura e com os indivíduos com quem convive, apropria-se da realidade, dela participa e a reinterpreta, especialmente pela ludicidade. A criança e seu brincar de imersão na vida, aventurandose nas descobertas, enfrenta desafios e se constitui.

Compreendemos que a criança vive suas experiências a partir de múltiplas linguagens, por meio de diferentes formas de ver, interpretar e interagir com o mundo, as coisas e as pessoas. Considerando essa concepção, a fala e a escrita não podem ser vistas como as únicas formas de comunicação, pois, muitas vezes, nos pequenos, a linguagem corporal, que inclui gestos e expressões diversas, revela a expressão do viver infantil. Nesse sentido, nossas formas de ver e ouvir as crianças, suas conquistas e dificuldades, precisam abarcar uma gama de possibilidades de linguagem que permitem que elas compreendam e sejam compreendidas. Pensemos, por exemplo, num bebê, que, antes mesmo de desenhar ou rabiscar, nos fala de muitas maneiras: com um sorriso, um choro, um balbucio, um corpo estirado ao chão, um olhar. Sua existência revela um conjunto de movimentos corporais que, muitas vezes, passam desapercebidos pelos adultos que com ele convivem.

Contudo, o desprezo dessas manifestações pode comprometer nossa maneira de conhecer o outro. Segundo Vianna (2008, p. 19), é por meio dos movimentos que internalizamos cada experiência e elaboramos a comunicação: "[...] antes de exprimir na matéria a sua experiência existencial, o homem a traduz com a ajuda do próprio corpo. Alegria, dor, amor, terror, nascimento, morte [....".

A potência de expressão que a criança carrega a auxilia na tarefa de se relacionar com o outro e com o mundo, e o movimento é peça chave nessa aventura do conhecimento de seus pares e das coisas que a rodeiam. Por isso, como já pontuamos, a ampliação das experiências sensoriais, expressivas e corporais encontram guarida quando damos espaço à ampla movimentação, respeitamos os ritmos da criança e lançamos desafios em seu cotidiano (BRASIL, 2009). Especialmente na infância, o movimento do corpo é essencial para o desenvolvimento motor, psicológico, intelectual, afetivo e social.

Santos e Moreira (2020) questionam se há espaço para o acolhimento da corporeidade da criança que vai à escola, dado o importante papel desta na formação dos sujeitos. Segundo os autores, impera a ideia de controle e docilização das ações infantis e um silenciamento da expressividade, sendo importante superar essa condição e buscar um caminho para além da instrumentalização das práticas educacionais. 
O processo de ensino-aprendizagem com as crianças precisa reconhecer o corpo como aliado e não apenas como um 'apêndice' a ser subjugado a regras e normas para o bom exercício da mente. Temos acompanhado que, desde os primeiros anos de escolarização, as crianças participam de rituais cotidianos que valorizam, estimulam e treinam a imobilidade do corpo, cujos encaminhamentos são entendidos como necessários para alcançar a aprendizagem.

A aprendizagem de conteúdos é uma aprendizagem sem corpo, e não somente pela exigência de o aluno ficar sem movimentar-se, mas, sobretudo, pelas características dos conteúdos e dos métodos de ensino, que o colocam em um mundo diferente daquele no qual ele vive e pensa seu corpo (GONÇALVES, 2001, p. 34).

A separação corpo-mente se manifesta na fragmentação de atividades, que se sobrepõem umas às outras, geralmente focadas em apostilas ou folhas xerocadas, com o corpo preso a uma cadeira, pela ausência do brincar. O esforço em manter a ordem e conseguir o domínio sobre o corpo se justificam em nome do futuro brilhante que esperaria as crianças, ou seja, não olhamos para a criança pelo que ela é, mas nutrimos a promessa do vir a ser, atropelando a infância com as exigências adultas.

Outra característica da escola [...] é que ela privilegia o futuro em detrimento do presente. Todo o ensino caracteriza-se por constituirse numa preparação para o futuro, esquecendo o momento existencial presente que a criança vive. De maneira geral a criança é levada a crer que, durante o período escolar, ela deve procurar construir uma base sólida de operações cognitivas, que a possibilitará produzir seu futuro invisível. Em função desse futuro abstrato, a criança aprende a postergar inúmeros interesses momentâneos ligados as suas experiências concretas. Dessa forma, a escola reflete, ao mesmo tempo perpetua, a forma de alienação do homem moderno (GONÇALVES, 2001, p. 35).

Nesse intento, o corpo não é visto em sua inteireza, mas representa um estado de espírito que deve ser controlado, governado por outrem. Paulatinamente, esse controle é internalizado e os sujeitos se autogovernam. Como nos lembra Foucault (1999, p. 29), a modernidade instaurou modos de vida em que o controle está no centro das ações desenvolvidas, seja no mundo do trabalho, familiar ou escolar. A disciplina foi exposta como a forma mais eficaz de exercício do poder, na conformação de corpos dóceis desde a mais tenra idade, prevalecendo a compreensão de que "[...] o corpo só se torna força útil se é ao mesmo tempo corpo produtivo e corpo submisso".

O corpo dócil pode ser visto como um corpo treinado e preparado, disponível às tarefas exigias de maneira rápida e eficaz. A sociedade disciplinar e seu investimento nos corpos, das populações e dos indivíduos, é descrita por Foucault (1999, p. 163-164), em que o controle se dirige 
SANTOS, A. C. N. DE; LIRA, A. C. M

[...] à eficácia dos movimentos, sua organização interna; a coação se faz mais sobre as forças que sobre os sinais; a única cerimônia que realmente importa é a do exercício. A modalidade enfim: implica numa coerção ininterrupta, constante, que vela sobre os processos da atividade mais que sobre seu resultado e se exerce de acordo com uma codificação que esquadrinha ao máximo o tempo, o espaço, os movimentos. Esses métodos que permitem o controle minucioso das operações do corpo, que realizam a sujeição constante de suas forças e lhes impõem uma relação de docilidadeutilidade, são o que podemos chamar as 'disciplinas'

Quando os mecanismos de disciplinamento e controle acabam por suprimir o corpo-criança, transformando-o, fabricando um corpo-aluno, torna-se impossível ou sem importância vivenciar as emoções, as alegrais e conquistas do ser criança. Cebulski (2014, p. 24-25) aponta a grande falha da educação em minimizar de forma excessiva as afetividades e destaca as consequências desse menosprezo:

Os crescentes índices de violência, depressão, ansiedade e demais distúrbios de caráter psiquiátrico, a desmotivação relacionada às atividades acadêmicas, a competitividade desenfreada, as crises nos mais diversos tipos de relações, e tantos outros graves problemas que vivenciamos são indicativos de que a educação, tal como tem sido conduzida, não vem cumprindo devidamente a sua função, que é a de desenvolver a nossa humanidade da melhor maneira possível.

O corpo assujeitado, corpo-aluno, é incompatível com o corpo-criança, explicitando o processo de objetificação naturalizado nas escolas. Num jogo coercitivo, "[...] os indivíduos tornam-se alvo de um poder exercido sobre eles e de um saber produzido através deles, com o qual passam a se reconhecer" (CARVALHO, 2005, p. 23). Assim, as identidades infantis são forjadas em práticas escolarizantes em que a corporeidade não encontra morada, sendo o corpo físico docilizado o objetivo final, com impactos abrangentes também sobre a mente.

O corpo-aluno que assume o lugar do corpo-criança introjeta a ordem e a disciplina que lhe foram impostas, habituando-se a não se movimentar, a não se maravilhar com as coisas do mundo. Como nos ensinou Foucault (1999), se no início a vigilância é exterior, aos poucos ela é internalizada, e os próprios sujeitos se autovigiam.

Do ponto de vista da linguagem corporal, a anulação compromete, inclusive, a vivência de uma respiração sadia, que não depende só de aspectos biológicos. Segundo Vianna (2008, p. 71), "Pessoas de corpo inexpressivo estão privadas de oxigenação. A partir do momento em que bloqueamos ou dificultamos nossa respiração interna, começamos a matar nossa sensibilidade, a intuição, todo o corpo". Dentro das paredes da escola, o sistema, seus aparatos e regras estão voltados para bloquear ou apenas não lidar com essa respiração, pela asfixia do corpo-criança ao desprezar os ritmos infantis. $\mathrm{O}$ corpo disponível, acumulador de experiências, com infinitas possibilidades de dialogar, de ser e estar no mundo, perde sua identidade para transformar-se no corpo-aluno, idealizado pela escola moderna. 
Guedes (2018), ao se referir à frase "Ninguém sabe o que pode um corpo", dita por Espinosa ${ }^{8}$, revela que é a potência que define os corpos, ou seja, ela pode ampliar ou restringir a depender das relações que vivenciamos. $O$ que experimentamos pode nos expandir ou limitar, compondo o que somos e como compreendemos o mundo.

Atualmente, a despotencialização do corpo-criança é empreendida em muitas situações, seja em casa, na escola ou por meio da tecnologia, sob o argumento de manter a previsibilidade, o controle e, em nome da segurança, da aprendizagem e da boa formação. A criança que corre, brinca, se relaciona é incompatível com o modelo de aluno esperado pelas instituições educativas. O próprio espaço escolar, com a distribuição do mobiliário e os brinquedos fora do alcance das crianças, atua na (con)formação do corpo-aluno. Como pontuam Santos e Moreira (2020, p. 2), "Ainda são recentes, entre nós, estudos e pesquisas que garantam a centralidade na corporeidade criança como sujeito existencial e que busquem refletir sob a ótica da inteireza de pensamentos, das ações corporais, do jeito de ser e estar no mundo-vida".

Ganha importância a reflexão sobre os encaminhamentos das instituições educativas voltados para o controle corporal, presentes em discursos, regulamentos, combinados, regras cujo objetivo é eliminar ou conter movimentos e controlar o pensamento. As filas, o sentar um atrás do outro, os tempos cronometrados, todos fazem parte de um cotidiano marcado pelo ponto de vista do adulto, que desconsidera o ser criança, suas necessidades e capacidades. Nesse universo, os sujeitos infantis, muitas vezes, não podem falar, não podem correr, não podem se sujar, tendo seus movimentos e ações subjugados a um conjunto de negações que se impõem sobre os corpos e mentes.

A primazia da obediência alienante que prevalece nos contextos educativos nada favorece à cidadania. Segundo Luengo (2009), o objetivo é dar prioridade à reprodução, própria do sistema capitalista. Pensar sobre as relações de poder, buscar entender como se materializam nas práticas cotidianas, é exercício imperioso para a defesa da criança e seu direito a uma educação de qualidade com lugar para a corporeidade. López-López e Galdino (2020) destacam a potência do corpo e da corporeidade nas práticas educativas e a importância de encontrar caminhos para uma educação mais viva, com aprendizagens significativas que valorizam as múltiplas linguagens. Negar o corpo pela primazia da fala e da escrita impõe um cotidiano que nega a criança, sua potência de vida.

\section{CONSIDERAÇÕES FINAIS}

Refletir sobre a relação entre corpo, educação e formação na infância torna-se relevante na medida em que um aspecto interfere na compreensão e dimensionamento do outro. A literatura evidenciou como, historicamente, o corpo foi, de início, compreendido como separado da mente, ou seja, o físico e o intelecto, as emoções e os sentimentos eram considerados dicotomicamente. A superação teórica dessa visão deuse pela defesa da integralidade dos sujeitos, da inter-relação entre corpo e mente e pelo reconhecimento do papel da cultura, do meio, na (con)formação dos modos de ser e

\footnotetext{
${ }^{8}$ Filósofo do século XVII.
} 
pensar. Ainda há que se concretizar essa integralidade na configuração das práticas pedagógicas.

Esse modo de compreender a vivência da corporeidade ganha relevância nos contextos educativos que trabalham com crianças pequenas e nos encaminha para valorizar experiências em que o corpo infantil encontre morada, possa existir em sua inteireza tanto física como mental. Na vivência infantil, os corpos são continuamente convocados a interagir, relacionar-se e, para que isso aconteça e impacte positivamente no desenvolvimento das crianças, as instituições educativas precisam rever e transformar suas práticas assentadas no controle e disciplinamento.

A reflexão aqui proposta chama a atenção para a necessidade de considerar a infância como tempo de descobertas, de conquistas, de aprendizados das diferentes formas de comunicação, incluindo a expressão corporal, o brincar, o falar, o agir, os quais revelam a diversidade de modos de vida e contextos de nossas crianças. Essa visão precisa ser acompanhada por um olhar que nos revela que a infância não é apenas um tempo de coisas boas, felizes, mas também inclui dissabores, angústias, tristezas, dificuldades (KORCZAK, 1981; ABRAMOWICZ, 1983).

As reflexões apresentadas permitiram reconhecer que o corpo-criança, cheio de vida, energia e movimento, defronta-se nas instituições educativas com a exigência de imobilidade e repetições para a incorporação dos gestos, dos hábitos, dos comportamentos ensinados e esperados, formatando o corpo-aluno. A criança, entusiasta e cheia de potência, conforma seu corpo nos moldes da disciplina no espaço escolar que funciona ancorado em relações de poder, cuja vigilância empregada pelos adultos se soma ao autocontrole e ao crivo de seus pares.

O conceito de corporeidade discutido nos ajudou a compreender que é por meio da relação dos sujeitos e seus corpos com o mundo que há a troca de saberes e o desenvolvimento de habilidades integradas à cultura. Para as crianças, o contato com o mundo, suas experimentações e descobertas, principalmente por meio das brincadeiras, proporciona crescimento e desenvolvimento. Infelizmente, o cotidiano institucionalizado das crianças pequenas restringe ou nega as experiências das crianças com o mundo que se dão especialmente pelo brincar.

É ludicamente que a criança participa com inteireza de sua cultura, troca saberes com seus pares, modificando-se a si mesma e ao mundo que a cerca. A urgência da soltura do corpo-criança se contrapõe à acinesia que os pequenos vêm sofrendo e fomenta a existência de uma corporeidade sadia dentro da escola. Ouvir as crianças, respeitar seus direitos e modos de vida ao invés de silenciá-las, proporcionar experiências significativas, são atitudes que precisam encontrar espaço nas instituições educativas. INSTITUTIONS 
ABSTRACT: The article aims to reflect on the child's body and corporeality and how they are lived and constituted in educational institutions. The text is of a bibliographic nature and the critical reflections undertaken help us to recognize that the established practices, spaces and relationships act to discipline and constrain children's bodies in order to produce the student body. Based on the theoretical basis, it was possible to recognize how historically education aimed at child subjects transforms the child-body into a student-body, a process established since early childhood education based on practices and rituals instituted and anchored in a set of surveillance strategies, sanctions and punishments. From the considerations about the children's subjects' ways of being in educational institutions, we recognize that the body and the corporeality, from an early age, become the object of attacks that end up canceling the children's characteristics and acting in the constitution of students adjusted to the school system.

KEYWORDS: Body. Child education. Power relations.

DISCIPLINAR Y AVERGONZAR: EL CUERPO INFANTIL Y SU (NO)HOGAR EN INSTITUCIONES EDUCATIVAS

RESUMEN: El artículo tiene como objetivo reflexionar sobre el cuerpo y la corporeidad del niño y cómo se vive y se constituye en las instituciones educativas. El texto es de carácter bibliográfico y las reflexiones críticas realizadas nos ayudan a reconocer que las prácticas, espacios y relaciones establecidos actúan para disciplinar y constreñir el cuerpo de los niños para producir el alumnado. Partiendo de la base teórica, fue posible reconocer cómo históricamente la educación dirigida a sujetos infantiles transforma el cuerpo infantil en cuerpo estudiantil, proceso establecido desde la educación infantil a partir de prácticas y rituales instituidos y anclados en un conjunto de estrategias de vigilancia, sanciones y castigos. A partir de las consideraciones sobre las formas de ser de los sujetos de los niños en las instituciones educativas, reconocemos que el cuerpo y la corporeidad comienzan, desde temprana edad, a ser objeto de ataques que terminan anulando las características de los niños y actuando en la constitución de los estudiantes ajustados al sistema escolar.

PALABRAS CLAVE: Cuerpo; Educación infantil; Relaciones de poder.

\section{REFERÊNCIAS}

ABRAMOVICH, F. (Org.). O mito da infância feliz. São Paulo: Summus, 1983.

BARBOSA, M. C. S. Por amor e por força: as rotinas na Educação Infantil. Porto Alegre: Artmed, 2006.

BRASIL. Diretrizes Curriculares Nacionais para a Educação Infantil. Ministério da Educação. Secretaria de Educação Básica. Brasília, DF: MEC, 2009.

CARVALHO, R. S. de. Educação Infantil: práticas escolares e o disciplinamento dos corpos. 2005, f. 193. Dissertação (Mestrado em Educação) - Programa de Pós-Graduação em Educação, Porto Alegre, UFRGS. 2005. 
SANTOS, A. C. N. DE $;$ LIRA, A. C. M

CHAGAS, J. e S. Cadáver desconhecido: importância histórica e acadêmica para o estudo da anatomia humana. 2001. 137f. Dissertação (Mestrado em Morfologia) Departamento Ciências Morfológicas - Universidade Federal de São Paulo - Escola Paulista de Medicina, 2001.

CEBULSKI, M. C. Um diálogo entre Vygotsky e o sistema teórico da afetividade ampliada: o teatro na educação básica e o desenvolvimento sócio emocional humano. 2014. 460f. Tese (Doutorado em Educação) - Setor de Educação, Universidade Federal do Paraná, 2014.

COLELLO, S. M. G. Alfabetização e motricidade: revendo essa antiga parceria. Cadernos de Pesquisa, São Paulo, n. 87, p. 58-61, nov. 1993. Disponível em: http://publicacoes.fcc.org.br/ojs/index.php/cp/article/view/927. Acesso em: 18 jun. 2020.

DAOLIO, J.; RIGONI, A. C.; ROBLE, O. J. Corporeidade: o legado de Marcel Mauss e Maurice Merleau-Ponty. Pro-Posições, Campinas, v. 23, n. 3, p. 179-193, set./dez. 2012. Disponível em: https://www.scielo.br/pdf/pp/v23n3/11.pdf. Acesso em: 18 jun. 2020.

FERNANDES, M. das G. M. O corpo e a construção das desigualdades de gênero pela ciência. Physis, Revista de Saúde Coletiva, Rio de Janeiro, 2009. Disponível em: https://www.scielo.br/pdf/physis/v19n4/v19n4a08.pdf. Acesso em: 18 jun. 2020.

FOUCAULT, M. A sociedade punitiva: curso no Collège de France (1972-1973). Trad. de Ivone C. Bendetti. São Paulo: Martins Fontes, 2015.

FOUCAULT, M. Vigiar e punir: o nascimento da prisão. Trad. de Raquel Ramalhete. Petrópolis: Vozes, 1999.

GUEDES, A. O. O corpo nosso de cada dia: corporeidade e formação de professores. Teias, Rio de Janeiro, v. 19, n. 52, p. 304-315, jan./mar. 2018. Disponível em: https://www.epublicacoes.uerj.br/index.php/revistateias/article/view/27937. Acesso em: 18 jun. 2020.

GONÇALVES, M. A. S. Sentir, pensar, agir: corporeidade e educação. Campinas: Papirus, 2001.

GOMES, R. Antropologia do corpo e modernidade. Caderno de saúde pública, v. 27, n. 11, p. 2277-2279, nov. 2011. Disponível em: https://www.scielo.br/scielo.php?pid=S0102311X2011001100022\&script=sci_arttext\&tlng=pt. Acesso em: 18 jun. 2020.

INFANTE, R. Fundamentos da dança: "corpo-movimento-dança". UNICENTRO, Guarapuava. 2011.

KORCZAK, J. Quando eu voltar a ser criança. São Paulo: Summus, 1981.

LABAN, R. Domínio do movimento. São Paulo: Summus, 1978. 
LE BRETON, D. A sociologia do corpo. Petrópolis: Vozes, 2007.

LIRA, A. C. M. Pedagogização da infância: refletindo sobre poder e regulação. Inter-Ação, Goiânia, v. 2, n. 33, p. 317-341, jul./dez. 2008. Disponível em: https://www.revistas.ufg.br/interacao/article/view/5270. Acesso em: 18 jun. 2020.

LÓPEZ-LÓPEZ, M. A.; GALDINO, G. R. A potência do corpo e da corporeidade na práticas e vivências educativas. Artes de Educar, Rio de Janeiro, v. 6, n.1, p. 129-140, 2020.

Disponível em: https://www.epublicacoes.uerj.br/index.php/riae/article/view/45830/32166. Acesso em: 25 set. 2020.

MARTINS, E. C. A corporeidade na aprendizagem escolar (Entrelaços fenomenológicos do pensar e agir). Educar em Revista, Curitiba, n. 56, p. 163-180, 2015. Disponível em: https://www.scielo.br/pdf/er/n56/0101-4358-er-56-00163.pdf. Acesso em: 23 jun. 2020.

MAUSS, M. As Técnicas Corporais. In: MAUSS, M. Sociologia e Antropologia. São Paulo: EDU/EDUSP, 1974.v. 2

MELO, J. M. de S. A medicina e sua história. Rio de Janeiro: Editora de Publicações Científicas Ltda, 1989.

MERLEAU-PONTY, M. Conversas-1948. São Paulo: Martins Fontes, 2004.

MERLEAU-PONTY, M. Fenomenologia da percepção. Trad. de Carlos Alberto R. de Moura. São Paulo: Martins Fontes, 2018.

NÓBREGA, T. P. da. Corpo, percepção e conhecimento em Merleau-Ponty. Estudos de Psicologia, Natal, v. 13, n. 2, p. 141-148, 2008. Disponível em: https://www.scielo.br/scielo.php?script=sci_arttext\&pid=\$1413-294X2008000200006.

Acesso em: 03 abr. 2020.

PROBST, M.; KRAEMER, C. Sentado e quieto: o lugar do corpo na escola. Atos de Pesquisa em Educação, Blumenau, v. 7, n. 2, p. 507-519, maio/ago. 2012. Disponível em: https://proxy.furb.br/ojs/index.php/atosdepesquisa/article/view/3163. Acesso em: 18 jun. 2020.

SALVADOR, G. D. D. Histórias e propostas do corpo em movimento: um olhar para a dança na educação. Guarapuava: UNICENTRO; Azul Editora e Assistência Gráfica, 2012.

SANTIN, S. Perspectivas na visão da corporeidade. In: MOREIRA, W. W. (Org.). Educação Física e esportes: perspectivas para o século XXI. Campinas: Papirus, 1993. 
SANTOS, A. C. N. DE; LIRA, A. C. M

SANTOS, A. C. R. F. dos. Corporeidade infantil: quando o corpo-criança é transformado no corpo-aluno. 2020. 104f. Dissertação (Mestrado em Educação) - Universidade Estadual do Centro-Oeste, Guarapuava, 2020.

SANTOS, J. C. dos; MOREIRA, W. W. A corporeidade criança vai à escola? Educação, Santa Maria, v. 45, p. 1-27, 2020. Disponível em: https://periodicos.ufsm.br/reveducacao/issue/view/1544/showToc. Acesso em: 14 out. 2020.

VIANNA, A.; CASTILHO, J. Percebendo o corpo. Rio de Janeiro: DP\&A, 2002.

VIANNA, K. A dança. São Paulo: Summus, 2008.

Aline Cristiane Ribeliro Ferreira dos Santos: Formada em Arte Educação pela Universidade Estadual do Centro Oeste - UNICENTRO (2016). Mestra em Educação pelo PPGE - Programa de Pós Graduação em Educação da Universidade Estadual do Centro Oeste - UNICENTRO.

Orcid: https://orcid.org/0000-0002-6835-4142

E-mail: opheliac_aline@yahoo.com.br

Aliandra Cristina Mesomo LiRA: Doutora em Educação pela Universidade de São Paulo (USP). Professora Associada do Departamento de Pedagogia e do Programa de Pós-Graduação em Educação da Universidade Estadual do Centro-Oeste/UNICENTRO, Guarapuava/PR.

Orcid: http://orcid.org/0000-0003-2945-464X

E-mail: aliandralira@gmail.com

Este periódico utiliza a licença Creative Commons Attribution 3.0, para periódicos de acesso aberto (Open Archives Iniciative - OAI). 